\title{
Spontaneous Thought and Goal Pursuit: From Functions such as Planning to Dysfunctions such as Rumination
}

\author{
Eric Klinger, Igor Marchetti, and Ernst H. W. Koster \\ Chapter 17 in Fox, K. C. R., \& Christoff, K. (in press), The Oxford Handbook of \\ Spontaneous Thought. Oxford, UK: Oxford University Press.
}

\begin{abstract}
Spontaneous thoughts occur by default in the interstices between directed, generally taskoriented thoughts or moments of perceptual scrutiny. Their contents are overwhelmingly related to thinkers' current goals, either directly or indirectly via associative networks, including to past and tentative future goals. They are triggered by ambient goal-related stimuli or segments of own thought. Most spontaneous thought segments are very brief, a matter of seconds, but may be much longer. Their typical brevity generally permits wide variation in content, reflecting the individual's current agenda of goals. Their evocation is accompanied by emotional responses that vary widely in type, valence, and intensity. These properties of the emotional accompaniments probably determine which content area receives priority for thought. Given these properties of thought flow, spontaneous thoughts are highly adaptive as (1) reminders of the individual's larger agenda of goals while occupied with pursuing any one of them, (2) promotion of planning for future goal pursuits, (3) review and deeper understanding of past goalrelated experiences, and (4) development of creative solutions to problems in goal pursuit. In the face of threats to successful pursuit of important goals or the prospect of failure, the same
\end{abstract}


mechanisms may occasion repetitive but unproductive thoughts about the pursuit, the consequences of the failure, or the self, and strong negative emotions steering the train of thought may lead to narrowing of its focus, thus producing rumination. The disposition to ruminate is in part a function of states of negative affect and individual differences such as strength of focus on particular thought themes, momentum of particular emotional states, and neuroticism. Rumination is a common occurrence during low mood or outright depression that accompanies the process of disengaging from goal pursuits that have become unrealistic or overly expensive. The typically reduced interest in alternative goals during this phase further limits the range of thought content and the individual's resources for re-engagement with gratifying goal pursuits. For assessment and clinical purposes, spontaneous thought content can potentially provide information not captured by other procedures. When an individual’s spontaneous thoughts are themselves problematic, empirically validated methods for improving the individual's motivational structure provide a likely best treatment strategy.

[354 words]

Keywords: spontaneous thought; current concern, daydreaming; mind-wandering; adaptive; maladaptive; goal; rumination, emotion, planning 
Under normal conditions, the brain never just rests. As circumstances change from, for example, focusing on tasks to seemingly aimless musing or from waking to the various phases of sleep (or the reverse of these), the parts of the brain that are most active change from one set to another. Studies of the contents of consciousness have long recognized this apparently unceasing activity, and the technology of brain imaging has permitted gradually revealing the neural reality that underlies it. Two important generalizations have emerged from these studies which are also central components of the Goal Theory of Current Concerns (Klinger, 1971, 1975, 1977, 2013; Klinger \& Cox, 2011a): (a) spontaneous thought represents the mental baseline; (b) the content of spontaneous thought is mainly related to personal goals.

\section{Basic Properties of Spontaneous Thought}

\section{Spontaneous Mentation as Baseline or Default Mental State}

First, as early observations suggested, spontaneous thought (in the sense of "unintended, nonworking, non-instrumental mental content that comes to mind unbidden and effortlessly"; Christoff, 2012, pp. 52; Klinger, 2009) constitutes a baseline state of mental activity that occurs irresistibly in the absence of instrumental, task-oriented mental activity (Klinger, 1971). Spontaneous thought in this sense includes mostly such states as mind-wandering and other forms of daydreaming. In parallel, early brain imagers discovered that when their research participants turned from task mentation to mind-wandering, certain brain structures, such as the posterior cingulate cortex, medial prefrontal cortex, and possibly medial temporal lobe, predictably became particularly active; they dubbed these the default mode network (e.g., Andrews-Hanna et al., 2010; Christoff et al., 2009; Mason et al., 2007; Raichle et al., 2001; Stawarczyk et al., 2011b), default here carrying the same meaning as the earlier term baseline. 
To be clear, mind-wandering is not the only kind of conscious content that can be observed while the default mode network is active. That is, other self-referential and perceptually decoupled content may also occur (e.g., Spreng et al., 2009). Moreover, mind-wandering is often interwoven with executive systems (Christoff, 2012; Christoff et al., 2009), with the default mode network being positively correlated with the frontoparietal control network during internally focused tasks (e.g., Spreng, Stevens, Chamberlain, Gilmore, \& Schacter, 2010). Still, mind-wandering is clearly a prominent part of the default mix (for a more extended discussion of the relationship between the default mode network and mind-wandering, see Klinger, 2013).

Mind-wandering accounts on average for between about a third and a half of conscious thoughts (Killingsworth \& Gilbert, 2010; Klinger \& Cox, 1987-88). It would therefore be surprising if it could have evolved in the absence of important contributions to human functioning.

\section{Content of Spontaneous Mentation as Principally Goal-Related}

A second important generalization is that the content of spontaneous waking thought and dreaming is prominently related to the individual's goal pursuits, directly or indirectly, including metaphorically. For animal species, pursuit and adequate attainment of goals is, of course, a categorical imperative for survival. Furthermore, progress toward one’s goals is an important determinant of an individual's positive affect (Klug \& Maier, 2015). It is therefore not surprising that a chief focus of thought, spontaneous and otherwise, is the pursuit of an individual's goals, great and small. The goal pursuits in mind-wandering are mostly those in the individual's current life but may also, by association in spontaneous mentation, be those of the past or contemplated future, as revealed through thought- or dream-sampling using probes (Hoelscher, Klinger, \& 
Barta, 1981; Klinger, 1978, 2009; Nikles et al., 1998). This view is also supported by indications of spontaneous planning during mind-wandering (Baird et al, 2011; Stawarczyk et al., 2011a)— presumably planning for action toward one of the participant's goals. Studies of thoughts retrospectively recalled as most thought about "today and yesterday" were also characterized, in comparison with things less thought about, as being about goals marked by stronger commitment or by obstacles to their attainment (Klinger, Barta, \& Maxeiner, 1980).

Spontaneous thoughts are probably triggered by cues (meaningful stimuli) that may be external in the environment or internal in the person's own mental activity and that are associated with one or another of the individual's goals. Such cues may take many forms, such as the name of a loved one or something associated in the person's mind with a loved one (or with an enemy, etc.), or a word, image, or smell associated with an ongoing goal pursuit, including cues related to failure to achieve a goal (Chatard \& Selimbegović, 2011, Study 6).

A growing literature indicates that becoming committed to pursuing a goal boosts the cognitive processing priority for cues related to that goal. Thus, knowing a person's goals is a good predictor of which cues (such as spoken words) the person will attend to, recall, and have thoughts or dreams about—namely, those that are associated with the person's own goals as compared with someone else’s goals (Hoelscher, Klinger, \& Barta, 1981; Klinger, 1978, 2009, 2013; Nikles et al., 1998). (The parallels in findings with thoughts and dreams become less surprising in light of the argument that dreams are partly akin to mind-wandering in regard to both content and neural substrates [Domhoff \& Fox, 2015].)

The processing priority may also be found in interference effects. For example, in the classic Stroop procedure, in which participants are under instructions to name as quickly as possible the color of the font of words displayed one at a time, participants typically respond more slowly 
when the meaning of the word conflicts with the color, such as green font for the word RED. Presumably, word meaning takes precedence in cognitive processing over font color. Similarly, reaction times (RTs) in reporting the font color of goal-related words are typically on average longer than they are to non-goal-related words (Johnsen et al., 1994; Riemann \& McNally, 1995; Gilboa-Schechtman et al., 2000; Fadardi \& Cox, 2008) or images. Presumably, the own-goalrelatedness of the word's meaning grabs processing priority over identification of font color, thereby slowing reporting of font color. This processing priority could readily account for the tendency of conscious mental content in mind-wandering to gravitate toward material related to the individual's own goals. The stimuli for shifts in the content of mind-wandering segments are presumably internal ones in the individual's own ongoing stream of thought.

Interestingly, a recent study provided evidence for the notion that attention allocation is strongly influenced at early stages by the goal-relatedness of information (Vogt, Lozo, Koster, \& De Houwer, 2011). In this study, individuals either received a disgust or a neutral induction. As expected, it was shown that a disgust induction elicited attention towards disgust-related pictures that were briefly presented. More importantly, individuals in the disgust induction condition also showed heightened attention for pictures representing cleanliness which is due to disgust triggering the goal to be clean and attention thus being allocated to means (e.g., cleaning products) of becoming clean.

It is, of course, hard to control particular segments of participants' thought stream experimentally so as to examine their role as internal cues to further thoughts. The evidence described above showed that subtle own-goal-related external stimuli strongly affected the content of thoughts and dreams, but those cues were external. However, in a different kind of interference method, Kopp, D’Mello, \& Mills (2015) instructed some participants to list the 
features of an automobile and other participants to list their to-do plans for the next five days. Subsequently, all read a scientific text and indicated whenever they became aware of their minds wandering to task-unrelated thoughts (TUTs) or to task-related interference (TRIs). As predicted, the participants who had just reminded themselves of their short-term goals reported more TUTs and displayed less comprehension of the text than did the control group, whereas the groups did not differ in TRIs. The difference in TUTs mediated the difference in comprehension. Presumably, recounting one’s own goals triggered more subsequent distracting thoughts, probably also about own goals. Other research (McVay \& Kane, 2013) has also shown with thought probes that displaying word triplets that contain words alluding to participants’ personal concerns, as compared with other word triplets, increased subsequent mind-wandering.

Mind-wandering is, of course, by definition thought that wanders off-task. However, Dijksterhuis and his colleagues (e.g., Dijksterhuis \& Meurs, 2006; Dijksterhuis \& Nordgren, 2006) have proposed that "unconscious thought", defined as "thought or deliberation in the absence of conscious attention directed at the problem” at hand (Dijksterhuis, Bos, Nordgren, \& van Baaren, 2006; pp. 1005), provides important contributions to goal-attainment, such as superior decision-making. Their investigations have provided evidence in support of this position (but see Nieuwenstein et al., 2015). However, this evidence is based on a procedure that, typically and tacitly, operationalizes unconscious thought as whatever mental processing occurs during a task designed to distract the participant from a previous assignment that is to be resumed after an intervening distractor task. This seems very similar to the operational definition commonly used for opportunities for mind-wandering except that the distracting tasks assigned by Dijksterhuis' group, such as the n-back task (i.e., pressing a space bar when the character on a screen is the same as one $\mathrm{n}$ trials ago), are intended to block all conscious thought. What we now 
know about mind-wandering makes it likely that this procedure reduces but does not completely block it. It remains an open question as to the extent or way that "unconscious thought” and mind-wandering are in fact different processes. Perhaps future brain-imaging research can address this question.

The reason for raising this point here is that one investigation (Bos, Dijksterhuis, \& van Baaren, 2008) finds clearly that, in the absence of an experimentally induced goal to complete a task later, the contribution of unconscious thought to that task disappears. This supports the view that continuing the processing of task-relevant information depends on having established the current concern that underlies a goal pursuit. Relatedly, a review of other evidence indicates that "goal completion dissolves the cognitive, affective, and behavioural effects of goal striving” (Oettingen, 2012, p. 34), indicating that successful goal pursuit ends the cognitive effects of the respective current concern.

\section{Duration and Frequency of Spontaneous Thought Segments}

Thought segments are on average very brief. A group of 20 participants, who had received practice with feedback at estimating brief time lapses, rated the durations of their latest thought segments prior to probes, and of the segments just preceding those, in both laboratory settings and, for 12 of them, while living their otherwise normal daily lives. A segment here was defined as a thought that is thematically homogeneous and ends when the topic shifts. These participants' median estimates of segment duration were 5 seconds in both laboratory and dailylife settings, with a mean of 9 seconds in the laboratory setting and 14 seconds (with a standard deviation of 22 seconds) outside the laboratory (Klinger, 1978). These participants rated their confidence in their own estimates as "very confident" 64\% of the time and as "moderately 
confident” 35\% of the time. Pope (1977) asked participants in a laboratory to signal with a key press every time their mind shifted to a new topic, which happened on average about 5 to 6 seconds apart. This agrees very approximately with the findings described above (Klinger, 1978).

These estimated durations applied to all of a participant's sampled thoughts, not just the spontaneous ones, but participants in Klinger’s (1978) sample also rated each thought on a variety of variables, including Directedness and Undirectedness, the latter being equivalent to spontaneity. The correlations of Undirectedness ratings with Duration for daily-life samples were -.18 for the latest thought segment and -.08 for the just-previous thought segment; the corresponding correlations for Directedness were .17 and .11. The corresponding correlations for Undirectedness in laboratory samples were -.05 and .00; for Directedness, they were .06 and .02. Clearly, these are all very small correlations. It therefore seems safe to consider spontaneous thoughts, which make up between about a third and a half of people's thought segments, to be of approximately the same durations as directed thoughts.

The implication is that mental content continually jumps from one goal-related topic to another in brief segments that may or may not reflect the same goal. A very rough estimate provides the generalization that waking mental activity over a 16-hour day contains about 4,000 such thought segments (Klinger, 1990), of which perhaps between about 1,300 to 2,000 are spontaneous. 


\section{Emotional Responses in Relation to Spontaneous Thoughts}

There are a number of reasons to believe that thoughts carry emotional charge and may, in fact, be triggered by at least low-amplitude, fragmentary emotional responses (protoemotional responses; Klinger, 1996). First, there are substantial intra-individual correlations, across words, between the strength of participants' self-rated emotional response to each word and the extent to which they rated each word as related to their “important concerns, problems, worries, or goals that currently preoccupy” them. These correlations range from .45 (Bock \& Klinger, 1986) to a set of correlations that ranged from 0.57 to 0.65 in four unpublished data sets.

Second, goal-relatedness of thoughts is associated with emotional arousal. For example, another investigation (Nikula, Klinger, \& Larson-Gutman, 1993) prompted participants for their thought content when experimenters observed unsolicited skin-conductance responses, which are often taken to indicate emotional response. Ratings for goal-relatedness of thoughts were at those times significantly higher than when participants' thoughts were sampled during electodermally quiescent periods. Using a different approach, inducing an affectively negative concern experimentally led to increased mind-wandering and, subsequent to the mind-wandering episodes, continuing negative affect, suggesting that the mental content of the mind-wandering contributed to maintaining the negative affect (Stawarczyk, Majerus, \& D’Argembeau, 2013; see also Watkins et al., 2015, in regard to “emotional extrapolation”).

Also, in a lexical-decision task (pressing a button as quickly as possible to indicate whether a letter on a screen was an X or a Y [Schneider, 1987]) one side of the screen contained words intended to be peripheral distracting stimuli and probably not consciously perceived. The emotional-arousal effect of the distractor words (as subsequently rated by the participants) was 
inversely correlated with reaction time to the letters being judged as $\mathrm{X}$ or $\mathrm{Y}$. That is, words that participants rated as emotionally arousing slowed their task response-gained higher cognitive processing priority over the assigned lexical decision-making — in a way similar to that found with goal-related words in the Stroop. That this really was an effect of emotion is supported by the finding that the interference with task responses was associated with participants' scores on the Affective Intensity Measure (Larsen \& Diener, 1987). Given the evidence above that goalrelated thoughts accompany emotional arousal and that mind-wandering mostly features goalrelated thoughts, it is of interest that mind-wandering is itself associated with pupillary dilation, often viewed as indicative of emotional arousal (Franklin et al., 2013).

This similarity between emotional arousal and goal-relatedness in the effects of distractor words on cognitive processing is consistent with the view that 'being goal-related' means 'being emotionally arousing'. It presumably follows that the emotional tenor of mind-wandering is to some extent determined by the affective quality of the emotional response to cues that accompanies or perhaps evokes the next segments of thought flow. Glowing recollections of a good time at a party, of recognition for an accomplishment, or of a loving social interaction would expectedly carry a strongly positive emotional charge. Recollections of personal rejection or failure- threats to or loss of important goal attainments-would expectedly carry a strongly negative emotional charge. Furthermore, mood at one time point is associated with the affective tone of subsequent thoughts (Poerio, Totterdell, \& Miles, 2013). Correspondingly, emotionally charged thought segments are likely to lead to further segments of similar affective quality, whether anticipation of future positive consequences in the case of a foregoing positive segment, or, in the case of foregoing negative segments, subsequent segments of self-examination, selfcriticism, anger at others with anticipation of future avoidance of them or revenge, and imagined 
future episodes of rejection, failure, or loss. With strong emotional charge, as when important goals are involved, the resulting thought stream may be funneled into loops of thematically and emotionally related or event repetitive content, as in rumination (rumination is discussed at greater length in a later section).

\section{Adaptiveness of Spontaneous Thoughts}

The above view on spontaneous thoughts suggests both adaptive and maladaptive consequences. That spontaneous thoughts must have significant adaptive benefits is a clear logical inference from the apparent fact that humans have evolved to spend up to half of their mental activity engaging in them.

The notion that such an ubiquitous process must have significant adaptive advantages for the human species has received recognition (Baars, 2010; Klinger, 1990; Smallwood \& Andrews-Hanna, 2013) but so far only limited research attention, although that is gradually changing, including integration with advancing neuroscientific findings (Andrews-Hanna, 2012; Andrews-Hanna, Smallwood, \& Spreng, 2014; Fox et al., 2015; Gruberger et al., 2011). From a purely inductive standpoint, based on informal observation of the contents of spontaneous thoughts, a number of possible benefits are already apparent.

\section{Keeping track of goals}

First, given the brevity of most mind-wandering segments and the large number of them during a particular day, and given the tendency for these segments to cycle through thematic material relevant to an individual's numerous current goals, it is apparent that mind-wandering serves the function of reviewing an individual's agenda of goals other than the goal being 
currently pursued. This must surely refresh memory of these other goals and, most likely, serve as a reminder mechanism for taking timely action.

\section{Promoting planning}

Second, given that a substantial portion of mind-wandering or daydream segments are future-oriented (Andrews-Hanna et al., 2010; Baird et al., 2011; Buckner et al., 2008; Klinger \& Cox, 1987-88; Smallwood et al., 2009; Smallwood, Schooler, et al., 2011), they provide an arena for spontaneous planning or contributions to planning. Indeed, there is now evidence for such a planning function. On the one hand, these spontaneous contributions are in most instances imaginary fragments that bear on goals and plans without providing a linear planning process (Schacter, 2012). On the other hand, there is no reason to believe that mind-wandering cannot wander onto and perhaps be interrupted by brief operant (i.e., instrumental) segments. Researchers discovered that mind-wandering often includes an interweaving of default-network activity with executive brain systems (Christoff, 2012; Christoff, Ream, \& Gabrieli, 2004; Christoff et al., 2009; Mason et al., 2007; Spreng et al., 2010). One would expect such a process to contribute to the formulation of concrete plans for future behavior, as found by Baird et al, 2011 and Stawarczyk et al., 2011a. For example, spontaneous imagery of an upcoming party might portray an awkward interaction with an individual who is expected to be present, which might stimulate some operant thoughts of how to handle that situation. Spreng et al. (2010), based on fMRI observations, proposed a three-network model of how this switching process happens. The three networks are the default-mode network, the dorsal attention network, and a frontoparietal control network. The first two have "an intrinsic competitive relationship” (Spreng et al, 2010, p. 303) whereas the third plays a key role in the switch back and forth. 


\section{Creative problem-solving}

It has long been recognized in popular culture that difficult problems requiring nonroutine and hence creative solutions can be benefit from merely allowing time to pass before trying to finalize them, as in the advice to “sleep on” the problem. It is likely that not only sleep but also periods of spontaneous mentation, such as mind-wandering, facilitate this kind of incubation. There are numerous anecdotal accounts of people having important insights into difficult problems during carriage rides, bathing, taking a walk or a nap, etc. - that is, activities conducive to spontaneous mentation (e.g., Klinger, 1990; Singer, 2009). Now there are also relevant controlled experiments.

Dijksterhuis and Meurs (2009), investigating the efficacy of "unconscious thought” (Dijksterhuis \& Nordgren, 2006), assigned participants to tasks such as finding creative names for pastas or unusual uses for a brick and placed them in one of three conditions: immediate responses, or responses following three-minute periods of either focused thought about the problem or a distractor task. In three experiments, the participants responded with more creative or divergent responses after the distractor task than after the other activities. The investigators hoped to design distractor tasks that would suppress conscious thought, but from what we know about mind-wandering — very brief segments, focused on unmet goals_-it seems unlikely that the suppression could have been complete (Singer, 1966). It is therefore likely but uncertain that spontaneous thoughts could have been responsible for the results.

However, Baird et al. (2012) provided participants with two opportunities to think of unusual uses for common objects. Between these opportunities, some participants engaged in a very undemanding task that would provide plenty of time for spontaneous thoughts, and others 
received a very demanding task that would limit spontaneous mentation. The group who had the undemanding interim task performed significantly better than the other group on the second opportunity to come up with creative solutions. Evidently the chance to engage in spontaneous thought, as in mind-wandering, fostered the necessary incubation of creative solutions in a way that improved performance.

\section{Reviewing past experiences}

Of course, coming up with new ideas often involves drawing on one’s past experiences. Also, there is pleasure to be savored when reliving one's past good times and successes, perhaps in relation to hopes for more of them. Furthermore, when faced with one's own limitations and failures, transcending these often thrusts one into scrutinizing what one might have done differently, sometimes leading to useful insights that improve performance later on. Indeed, the contents of spontaneous thoughts and dreams include a substantial portion of memories and reflections on past events (Andrews-Hanna et al., 2010a; Klinger \& Cox, 1987-1988), especially during negative moods (Smallwood et al., 2011; Smallwood \& O’Connor, 2011). Reviewing past experiences for benefits to future endeavors is presumably advantageous in reaching one's goals.

\section{Reduced delay discounting}

Delay discounting is the phenomenon in which people, given the choice, prefer to receive smaller rewards soon rather than larger rewards later. That is, they presumably discount the value to them of the reward the more remote it will be in time. This preference may keep a person from maximizing well-being by settling for less than is available, be it money, career satisfaction, or a solid personal relationship. There is evidence that people whose minds wander more than others 
display less delay discounting (Smallwood, Ruby, et al., 2013), presumably therefore displaying more patience and arriving at more prudent choices. Unfortunately, because this evidence is correlational rather than experimental, one cannot be sure regarding the direction of causality.

\section{Consolidation of memories}

There is ample evidence that sleep helps to consolidate long-term memories (e.g., PaceSchott, Germain, \& Milad, 2015), especially during rapid-eye-movement (REM) sleep (McDevitt, Duggan, \& Mednick, 2014) and especially with regard to goal-relevant features (Bennion, Payne, \& Kensinger, 2015). It now appears that periods of spontaneous thinking confer a similar, albeit weaker, consolidation benefit. In an extensive review of relevant literature, Christoff et al. (2011) concluded that "recent findings suggest that the off-line processing that occurs during periods of rest is associated with the kind of memory consolidation processes that occur during sleep” (p. 264).

\section{Superiority in shifting between internal thought flow and external stimuli}

There are individual differences in control over the direction of attention between internal and external processes. The ability to shift back and forth appears positively related to the individual's working memory capacity (Rummel \& Boywitt, 2014). Additionally, trait measures of mind-wandering appear inversely related to the size of attentional blinks (Thomson et al., 2015). That is, when individuals are presented with a pair of stimuli in rapid enough succession, they do not register the second of those stimuli. The maximum inter-stimulus interval for this to happen is the size of an individual's attentional blink. In the study by Thomson et al., high scores on trait mind-wandering predicted shorter blinks, meaning that people whose minds wander more can on average shift more rapidly than others to the second stimulus in such a pair. 
Thomson et al. suggest that this is an indication of adaptively finer control over the focus of attention.

\section{Facilitating action toward goal-attainment}

Setting goals and moving on them generally begin with mental processes, often spontaneous, that recognize the desirability of an outcome, its attainability, and the means necessary for attaining it. It is, of course, difficult in observational research to disentangle these processes for purposes of establishing what leads to what. The closest that investigators have come so far is by instructing human participants to initiate daydream-like experiences and to vary something about the nature of these experiences, such as what the person might look forward to enjoying as a result of goal attainment or the obstacles that the person might imagine having to overcome (e.g., Oettingen, Pak, \& Schnetter, 2001). These imaginal segments are clearly not completely spontaneous in regard to their initiation and certain features of content, but once initiated and broadly determined by the investigator, they then unfold in perhaps partly spontaneous fashion. Experimental evidence indicates that induced daydreaming of this kind can influence subsequent real-life goal attainment. Oettingen et al. (2001) have in a number of studies established that optimal goal-attainment "requires explicit, simultaneous mental elaborations of both the desired future and present reality as instigated in the mental contrasting procedure” (p. 748), as for example reaching health-promoting goals (Johannessen, Oettingen, \& Mayer, 2012), exercise goals (Sheeran et al., 2013), and a variety of goals in a depressed sample (Fritzsche et al., 2016). Dwelling only on the pleasures of attainment or only on the obstacles in its way tended to be counterproductive in leading participants to reach their goals (e.g., Oettingen, 1996), as, for instance, in their teachers' ratings of actual achievement (Oettingen et al., 2001). Other studies of thoughts initiated by experimental instructions but allowed to unfold 
spontaneously have also found effects on intentions or actions likely to advance particular goal pursuits (e.g., Gollwitzer, 1990; Gollwitzer, Heckhausen, \& Ratajczak, 1990; Nenkov \& Gollwitzer, 2012). Whether these findings with only partially spontaneous thoughts will transfer to the effects of fully spontaneous thoughts remains to be demonstrated. (For a summary of research related to mental contrasting and prospective thinking, see Oettingen, 2012).

\section{Costs of Spontaneous Thoughts}

Research on the consequences of mind-wandering has focused heavily on its costs in the form of attentional lapses and degraded performance. However, it is important to keep in mind that neuroscientists became interested in mind-wandering and the default mode network as their participants switched from working on tasks to more relaxed intervals between tasks (Raichle et al., 2001). Mind-wandering occurs most often when the brain is less than fully occupied with tasks (such as during rest or undemanding tasks) or the external environment (e.g., AndrewsHanna et al., 2010a), when it is often safe to decouple brain activity (Smallwood, Tipper, et al., 2013) briefly from the external environment and ongoing tasks.

Because of this timing, there may be only modest impacts of mind-wandering on performance, but in other cases the impact can be substantial. Mooneyham and Schooler (2013) have presented an extensive review of empirical work on these costs, which include impaired comprehension when reading, impaired sustained attention to tasks, poorer performance on measures of working memory and general aptitude, and, on average, lowered mood. Since the publication of this review, Mrazek, Phillips, et al. (2013) have similarly reported impaired reading comprehension associated with prompt-assessed mind-wandering. A number of further studies have found additional costs: attentional lapses associated with impaired performance on the Stroop task (Unsworth \& McMillan, 2014), a significant relationship between mind- 
wandering proclivity and frequency of falls in older adults, presumably at least partly because of inattention to external stimuli (Nagamatsu et al., 2013), particularly in the left visual field (Kam, Nagamatsu, \& Handy, 2014), and reduced empathic responses to others’ physical discomfort, as assessed by participants' ratings and electrophysiologically with event-related potentials (Kam, Xu, \& Handy, 2014). By contrast, when leaving aside its perseverative, ruminative forms, mindwandering appears unrelated to most measures of health (Ottaviani \& Couyoumdjian, 2013; Ottaviani, Shapiro, \& Couyoumdjian, 2013).

Nevertheless, the cognitive impairment found in these studies must be qualified by other findings that even during mind-wandering people retain some sensitivity to external cues when these relate to potentially important matters or when a stimulus is unexpected (Kam et al., 2013). This conclusion is consistent with sleeping or otherwise occupied participants' disproportionate response to and incorporation of unexpected cues related to their goal pursuits (Hoelscher et al., 1981; Klinger, 1978). Furthermore, the interference of mind-wandering with task activity appears to affect especially response inhibition and working memory but not set-shifting (assessed in this case by delays caused after shifts in task rules within a series of trials; Kam \& Handy, 2014). The costs of mind-wandering to task performance are therefore apparently different for different aspects of performance and different kinds of external cues, the brain seemingly weighing the relative importance of external information versus maintaining the ongoing stream of thought (Handy \& Kam, 2015).

\section{Spontaneous thoughts and mood}

The findings for cognitive costs of mind-wandering are easily understandable. Perceptual decoupling is bound to interfere to some extent with absorbing one’s reading material and to 
distract from other ongoing tasks, including, of course, those that are measures of a person's cognitive capacity. Mooneyham and Schooler's (2013) generalization regarding lowered mood, however, must be treated with caution.

The generalization that mind-wandering lowers mood was misleadingly emphasized in the title and summary statements of an otherwise important article by Killingsworth and Gilbert (2010), an experience-sampling study with a huge sample. Close inspection of their data fails to support the generalization that mind-wandering as such lowers mood, only that the thematic content of mind-wandering segments influences mood. Inasmuch as minds wander to concerns about one's own goal pursuits, especially those that are still incomplete and those that may be in trouble (Klinger, Barta, \& Maxeiner, 1980), one might expect lower, more serious moods on average. However, in Killingsworth and Gilbert's own data, participants rated 42.5\% of their mind-wandering episodes as about something "pleasant," with mood then averaging slightly above the overall mood average, roughly equaling mood when not mind wandering. They rated $31 \%$ of the remaining mind-wandering episodes as about something "neutral," with average mood slightly below overall average but above the mood scale’s midpoint. Participants rated mood as sharply below overall average and below the scale midpoint only during the $26.5 \%$ of mind-wandering samples that they characterized as about something "unpleasant.” Thus, only particular thought content, not mind wandering as such, was associated with substantially lowered mood (cf. also Smallwood \& Andrews-Hanna, 2013; Stawarczyk et al., 2012). This was also the conclusion reached in subsequent experience-sampling studies (Marchetti, Koster, \& de Raedt, 2013; Poerio, Totterdell, \& Miles, 2013; see also, Fox, Thompson, Andrews-Hanna, \& Christoff, 2014). 


\section{Maladaptive and excessive daydreaming}

There has recently been an upsurge of interest in a condition in which people spend large amounts of time in imaginative daydreaming, usual involving imaginary companions or casts of characters that recur over time, sometimes as long as years, and gain a kind of quasi-reality (Bigelsen \& Schupak, 2011; Schupak \& Rosenthal, 2009). Interestingly, an early case report was documented by Féré in his La Pathologie des émotions (1892/1899). M. M. was a 37 years old, commercial man, married and with children, that suffered from long periods of absentmindedness. During these zone-outs, he was somewhat insulated from the surrounding environment or carried on his daily duties in a rather unconscious and mechanical way. Nevertheless, his daydreams were very structured and coherent, given that in his imaginary life "M. M. had constructed at Chaville on the borders of the wood, a pavilion surrounded by a garden. By successive additions the pavilion became a chateau, the garden a park; stables horses and pieces of water were introduced to ornament the domain. [...] A woman arrived to animate this scene: two children were born, it only remained to make this ideal manage legitimate. This was the only drawback to the happiness of our dreamer” (Féré, 1892/1899; pp. 316). Although this is an anecdotic report and does not represent the virtually unlimited variety of people's daydreams, the generation of vivid and emotionally salient, imaginary second lives recurs in recent reports of excessive daydreaming too (Bigelsen \& Schupak, 2011).

Importantly, recent accounts show that excessive daydreamers are fully aware that the persons depicted in their daydreams are fictional — there is no question here of delusion or other psychotic phenomena — and the range of the daydreamers' ability to function in real life may range from excellent to seriously impaired. These daydreamers appear to develop an attachment to their daydream sequences that makes it hard to abandon them. Attempts to suppress them may 
lead to a yearning, even grief over their loss. These daydreamers are variably accepting or distressed by their habitual daydreaming, especially if they perceive that the daydreams interfere with fully actualizing their potential in real-life goal-attainment.

It is unclear to what extent unusual amounts of habitual fanciful daydreaming can be considered a particular psychological disorder. Certainly if it distresses or significantly handicaps the daydreamer and the daydreamer feels incapable of controlling it, it can at least be considered a condition that merits clinical intervention. However, its manifestations vary enough across daydreamers that there is no clear single psychopathology with which it can be classified. In some ways it qualifies as obsessive thought, but it seems distinct from that diagnosis in that, whereas its existence in this quantity distresses the daydreamer, the experience of it while it happens feels positively satisfying, and suppressing it leads to grief-a sense of loss of the daydreamed pseudo-reality—rather than to anxiety. It has addictive properties, but at this point there appears to be no research that establishes these. Addiction is a matter of warped decisionmaking, warped choices. In the case of addiction to substances such as alcohol there are physical changes that skew decisions by overweighting the subjective value of the substance. It is unclear that daydreaming can instill the same changes. However, it is known that imagining perceptions or actions engages much of the brain's systems that would be engaged by actual perceptions and actions (Kosslyn, Thompson, \& Alpert, 1997). Perhaps longer-term imagining of fictional individuals can foster emotional attachments in the same way that extended personal contacts can foster emotional attachments to actual others. Terminating the fictional relationship may then yield a goal-disengagement process (Klinger, 1975, 1977; Klinger \& Cox, 2011a) somewhat similar to that produced by the loss of a valued real other person.

\section{Rumination}


Rumination is a form of repetitive self-focus that leads to and exacerbates depressive symptoms (Nolen-Hoeksema, Wisco, \& Lyubomirsky, 2008; Spasojevic \& Alloy, 2001). Rumination has been conceptualized in various ways, emphasizing either the trait versus the context-dependent nature of rumination (Smith \& Alloy, 2009). Moreover, various theories have provided different proposals on the main triggering events of rumination, which include negative mood as well as goal nonattainment (Smith \& Alloy, 2009).

\section{The Current Concerns Approach to Rumination. The Goal Theory of Current Concerns} described above (e.g., Klinger, 1977, 2013; Klinger \& Cox, 2011a) is helpful in explaining many of the key features of rumination. That is, goal-related cues, presumably including those in one's own thought stream, carry varying degrees and kinds of emotional charge and receive processing priority. Thoughts with strongly emotional content would have a high likelihood of evoking associated subsequent thoughts. These are also likely to carry a similar valence of emotional charge (positive or negative). This process is apparent in, for example, people happily in love, where affect is predominantly positive, but also in people grieving over a rejection, loss, or significant failure, especially while they are disengaging from their seemingly doomed goal (Klinger, 1975, 1977; Klinger \& Cox, 2011a), when affect is predominantly negative. The focused nature of the resulting streams of thought is precisely what we observe in rumination. Given the role of emotional response in this process, one would predict that individuals high in trait affectivity would be especially prone to fall into ruminative states. The frequently demonstrated high correlation between trait rumination and measures of negative affect supports this prediction (e.g., Watkins et al., 2015).

In support of the idea of narrowed cognitive processing of goal- and emotion-related cues, Grol et al. (2015) instructed participants to imagine an emotionally wrenching scenario (having 
just run over people with one’s car) and then either dwell on their negative feelings about it, or engage in problem-solving thinking. In a visuo-spatial task where participants needed to process self- vs non-self-related stimuli and detect targets in the periphery, participants high in trait rumination showed attentional narrowing toward personally relevant stimuli, with reduced retention of personally irrelevant peripheral stimuli. Given the close relationship between trait rumination and negative affectivity, it would appear that the strong negative emotions provoked by the ruminative instructions to focus on an emotionally devastating scenario led to thoughts responding repeatedly to ongoing emotionally charged stimuli, both internal (ideation) and external (self-referential experimental stimuli), thereby maintaining the narrow focus of rumination. This notion of difficulties in controlling attentional processing priorities can be related to a large body of research on information-processing and rumination, to which we now turn.

\section{Individual differences and impaired attentional disengagement that moderate cognitive} and emotional mechanisms in rumination. Nothing in the Current Concerns approach excludes other factors from operating in rumination, such as individual differences in attentional focus, inhibitory ability, or properties of working memory and executive control functions (e.g., Whitmer \& Gotlib, 2013). On the one hand, Current Concerns Theory describes mechanisms that govern the flow of spontaneous thoughts in general and indicates how these can operate to produce ruminative thought. Individual differences enter only insofar as different individuals are committed to different sets of goals and vary in the properties and strength of their emotional reactions. However, this formulation can be mapped onto theories that emphasize the cognitive processes related to rumination and that focus on the way in which certain emotionally salient 
thoughts receive cognitive processing priority. These theories are interesting to explain the persistence of rumination despite efforts to control this process.

Key mechanisms for the cycling in rumination within a narrow content field have been proposed in a number of theories. Many of these theories emphasize individual differences in cognitive processing styles. For instance, Attentional Focus theory (Whitmer \& Gotlib, 2013) provides a variable of individual-differences in the degree to which individuals constrict their attention and thought content to particular cognitive themes after they are started. This constriction is enhanced in negative mood states and weakened during positive moods. An individual's typical degree of constriction would moderate the likelihood that a negatively toned ruminative stream, once started, will continue.

Individual differences in emotional extrapolation, posited by Watkins et al. (2015), refers to the likelihood that an initial mood state associated with some event, presumably including a thought segment, will persist to color expectancies for subsequent events. Current Concerns Theory also posits some degree of such emotional continuity, in that the thematic content of an emotionally potent, goal-related thought segment is predicted to lead by association to thematically and emotionally related (but not identical) subsequent thought segments. This hypothesized continuity is confirmed by findings of negative affect being maintained across mind-wandering segments (Stawarczyk, Majerus, \& D’Argembeau, 2013). Watkins et al., moreover, theorize that the extent of such continuity constitutes a kind of individual trait. People high in emotional extrapolation would experience amplified emotional continuity. When the emotion is predominantly negative, as in trait negative affectivity (Tellegen et al., 1988), the trait would dispose toward greater likelihood of rumination. 
The impaired disengagement factor posited by Koster et al. (2011) as a prominent route toward depression refers to impaired control of attention that weakens the individual's ability to switch from a stream of negative repetitive thoughts to something more constructive that might help to dispel the negative mood. Importantly for this formulation, Koster et al. propose that, with sufficient repetition and progressive impairment of attentional control, the resulting rumination becomes habitual, further hindering its interruption and redirection. This approach is, then, not primarily an individual-differences approach but suggests a pathogenic extension of the thought-flow processes described above.

Thus, these important approaches identify different possible mechanisms responsible for individual differences in susceptibility to rumination by moderating the processes posited by Current Concerns Theory, whose model assumes that, with a powerful enough emotional tone, any goal pursuit (or failed pursuit) can become the subject of repetitive thought by any individual. Such repetitive thought is tantamount to rumination, or may be so in the presence of certain additional qualities, depending on the definition of rumination.

Interesting empirical support for information-processing theories of rumination comes from studies that attempt to experimentally improve attentional or cognitive control where rumination and depressive symptoms are studied as outcome variable. For instance, in a recent study where individuals with heightened levels of rumination were allocated to either a cognitive control training versus an active control condition, it was observed that individuals undergoing cognitive control training for two weeks showed lower emotional reactivity to a lab stressor as well lowered levels of depressogenic rumination during a subsequent exam period (Hoorelbeke, Koster, Vanderhasselt, Callewaert, \& Demeyer, 2015). 
Response Styles and Control Theories of Rumination. The most influential theory of rumination is currently still the response styles theory (RST), which defines rumination as “behaviors and thoughts that focus one’s attention on one’s depressive symptoms and on the implications of those symptoms” (Nolen-Hoeksema 1991, pp. 569). According to this theory, individuals react to negative mood by initiating ruminative processing with the aim of enhancing their self-understanding, which unfortunately leads to a paradoxical increase in negative mood (Lyubomirsky \& Nolen-Hoeksema, 1995). Within the RST, two specific ruminative subtypes have been defined and are worth mentioning: reflective pondering and depressive brooding (Treynor, Gonzalez, \& Nolen-Hoeksema, 2003). Reflective pondering is considered the less maladaptive form of rumination as it reflects the extent to which individuals try to improve their mood by engaging in problem-focused thinking. Brooding is considered the more detrimental form of rumination, as it represents “a passive comparison of one’s current situation with some unachieved standard” (Treynor et al., 2003, pp. 256).

Importantly, Martin and Tesser, consistent with earlier current-concerns theory and evidence regarding depression (Klinger, 1975, 1977; Klinger, Barta, \& Maxeiner, 1980), proposed a control theory account of rumination. This theory proposes that, as in the earlier current-concerns account of depression, state rumination is initiated by, and focuses on, a perceived discrepancy between one's goals and one's current state and continues until the goal is either attained or abandoned (Martin \& Tesser, 1989, 1996). Compared with RST, this account is focused less on depressed mood but can be applied more broadly to a wide range of circumstances. Interestingly, it has been found that cueing unresolved personal goals indeed was associated with an increased number of negative ruminative thought intrusions during a sustained 
attention-to-response task compared with cueing a resolved personal goal (Roberts, Watkins, \& Wills, 2013).

In an attempt to link the RST and the control theory of rumination, Watkins and NolenHoeksema (2014) proposed that rumination can be conceptualized as a mental habit (Hertel, 2004) that starts with episodes of self-focused repetitive thought triggered by goal discrepancies that become habitual through an automatic associative process between repetitive thinking and its context (e.g., physical location, mood). When, over time, these contexts trigger a passive focus on negative content combined with low levels of concrete thinking (see Watkins, 2008), the habit of depressive rumination is acquired. The latter type of habitual rumination is thought to be context-independent of goals and resistant to change.

Rumination and spontaneous thoughts. Given the relevance of goals and mental habits in spontaneous thoughts, one might suspect a rather large overlap between ruminative thinking and daydreaming. However, correlational studies clearly report only moderate correlations (Epel et al., 2013; Marchetti, Van de Putte, \& Koster, 2014). One explanation for this is that the term daydreaming is often used to refer specifically to fanciful mental streams, whereas rumination is generally serious and uncreative. In these senses, “daydreaming” and rumination are by no means the same phenomenon, even though both can usually be construed as instances of mindwandering and both are generally instances of spontaneous thought. In a new integrative framework aiming to understand the link between spontaneous thought and cognitive risk factors, Marchetti, Koster, Klinger, and Alloy (2016) propose that spontaneous thought, defined most broadly, can act as a context in which cognitive risk factors for depression such as rumination (but also thoughts of hopelessness, negative self-esteem, and cognitive reactivity) can be readily expressed, which is especially the case in conditions of heightened negative 
affectivity. In that sense, rumination is a specific subtype of spontaneous thought characterized by dominant negative thought content that is processed in an abstract and repetitive way so as to lock the train of thoughts into a thematically narrow content channel (Klinger, 2013; Watkins, 2008). Here it is important to note that this differs from many other instances in which spontaneous thought unfolds in an open, expansive, and divergent way (Marchetti et al., 2014; Watkins, 2010).

An interesting finding in this regard is empirical evidence showing that the affective consequences of spontaneous thought are multi-factorially determined based on the presence of individual-differences variables that heighten the susceptibility to engaging in state rumination (Marchetti, Koster, \& De Raedt, 2013). More specifically, rest-related spontaneous thoughts seem capable of shaping transitory ruminative thoughts in individuals showing, primarily, medium to high levels of trait cognitive reactivity and, secondarily, significant trait levels of ruminative brooding.

\section{Clinical Implications}

Traditionally, clinical interventions have targeted only selective kinds of spontaneous thought, such as maladaptive aspects of daydreaming and rumination, which show partial overlap with spontaneous thought (Marchetti et al., 2016; Watkins, 2010). However, examining the content and, perhaps, frequency of spontaneous thought in general could have some interesting clinical implications that are worthy of further examination. 


\section{Spontaneous Thought as Ancillary Information about Motivational Structure}

Broadly speaking and in keeping with a transdiagnostic approach, psychopathology is often characterized and maintained by problematic goals architecture. This can take a number of different forms. First, psychopathology such as anxiety and depression is frequently characterized by strong avoidance-related goals (see Hayes, Wilson, Gifford, Follette, \& Strosahl, 1996), often based on negative experiences and avoiding danger, rejection or hurt. This has important consequences for the cognitive processing of situations. For instance, for someone with social anxiety and the goal to avoid rejection by others, a social situation may cue attention to social threat and the context-specific means to reach safety (e.g., excuses to leave a gathering early), which can impair new learning and maintain threat-related beliefs. Frequently, such avoidance-related goals outweigh other more positively oriented goals so as to render individuals less likely to process positive information and/or actively pursue desired outcomes.

Given the dependence of spontaneous thought content on an individual's goals, these processes can be predicted to determine the content of the individual's thought flow. Although cognitive therapies try to change clients’ beliefs and mental habits as a way to change behavior, it is ultimately the client's behavior and affect that the therapy tries to influence. Insofar as spontaneous thought content is itself troublesome, these procedures have some merit, but altering a client's pattern of goal pursuits — the client's motivational structure - can also predictably contribute to changed cognitive processing and spontaneous thought flow. Thus, one strategy for changing troublesome spontaneous thought flow is to change the motivational structure- the individual's set of goals — that largely determines its content and frequency. 
Psychopathology can also be rooted in negative life events where individuals see important goals blocked (Klinger, 1975, 1977; Klinger et al., 1980). Here it is crucial for individuals to be capable of disengaging from unattainable goals and to re-orient and engage with goals that are more attainable. For various reasons (e.g., perfectionism, high standards, high valuation of the goal, lack of promising alternative goals, etc.) individuals can experience problems with disengaging from desired but unattainable goals or re-engaging with new goals. These states powerfully impact spontaneous thought content and affect.

Based on our theoretical position that the content of spontaneous thought has important links to each individual's goals, this content (such as mind-wandering, which is pervasive and often adaptive but may sometimes be viewed as interfering and disruptive) can in the therapeutic context be used in multiple ways, for instance as diagnostic information to aid in obtaining a clear view of the client's goal structure. The content of spontaneous thought and, probably, night dreams can signify or help to clarify individuals' motivational and cognitive structure (Beck, 1971/2004; Klinger, 1971). There are validated measures of goal structure in questionnaire form, such as the Motivational Structure Questionnaire and Personal Concerns Inventory (Cox \& Klinger, 2011a; Klinger, 1987; Klinger \& Cox, 2011b), but these rely on clients' memories and self-insights. Inferences from examination of clients' spontaneous thought content may add important information.

\section{Modifying Spontaneous Thought Content by Modifying Motivational}

\section{Structure}

Assessing motivational structure is important for treatment of a wide variety of conditions, perhaps especially but not exclusively such as depression, addiction, alienation, 
aimlessness, and goal conflicts. These may require interventions aiming to replace maladaptive motivational structures with more adaptive ones. For instance, within the Systematic Motivational Counseling framework, validated techniques have been developed to identify maladaptive goals and then help clients disengage from them in favor of more realistic and attainable goals (Cox \& Klinger, 2011b). The efficacy of this type of intervention focusing on clients' motivational structure rather than solely on the cognitive and/or behavioral aspects has recently been documented in alcoholic patients (Cox, Fadardi, Hosier, \& Pothos, 2015), miscellaneous substance abusers with traumatic brain injuries (Cox et al., 2003), and group treatment in a general clinical population (Fuhrmann, Schroer, \& de Jong-Meyer, 2011).

The general plan of these interventions is first to assess motivational structure (the types of goals chosen, the degree of commitment to and valuation of each, and expectancies of success) and then to discuss the findings with regard to such matters as the interrelationships among the goals, the degree to which the valuation is the client's own versus someone else's whom the client is trying to satisfy, the reasonableness of the expectancies, conflicts among the goals and possible resolution of them, shifting from aversive to appetitive goal pursuits, disengagement from inappropriate or fruitless goals, possible additional or alternative goals that fit the client's own true values and might provide greater satisfaction, and realistic steps that might render discouragingly difficult goals attainable. The goal of these interventions is, of course, a more adaptive motivational structure, which should brighten mood and help clients abandon destructive behaviors such as substance abuse. In addition to the already cited studies supporting this hypothesis, higher adaptive motivational structure has been found related to lower alcohol consumption in people whose consumption has led to objective life difficulties, such as in the workplace, family and other social relationships, the legal system, health, etc. (Cox 
et al., 2002). In clients with low scores on adaptive motivational structure, there was no correlation between difficulties incurred from drinking and amount consumed. Although this result was correlational and hence does not permit a firm conclusion about causality, it seems a reasonable inference that highly adaptive motivational structure facilitates reducing injurious alcohol consumption. Although these investigations did not assess spontaneous thought content, their interventions can be predicted to have changed it as well.

As indicated above, goal commitments establish cognitive processing priorities that direct attention to goal-related cues. This can become problematic for a variety of conditions and has been investigated with substance abusers. In much of the world, for example, grocery stores sell alcoholic beverages and often place these in locations that are hard to overlook. Heavy imbibers report that these displays rivet their attention and, even if they are trying to reduce alcohol use, nevertheless make it harder not to buy. Similarly, when faced with a series of words, the attention of heavy drinkers is drawn to words associated with alcohol use (as to other important goals). One clinical intervention has been designed to reduce this problem by retraining attention. Using Stroop-like interventions, participants adopt the goal of attending to the font color instead of to the semantic meaning of alcohol-related words or to the color outlines around various depicted bottles. The administrator provides feedback and encouragement. Results show that a series of such training sessions reduces the processing priority of alcohol cues and reduces the amount of alcohol subsequently consumed for up to a three-month follow-up assessment (Cox et al., 2015; Fadardi \& Cox, 2009). Although these investigations are still in their early stages (Koster \& Bernstein, 2015) and so far have not assessed spontaneous thought, the effect on attentiveness - as one kind of cognitive processing - can be predicted to have also affected thought content, among other clinical outcomes. 


\section{Training for Concrete Versus Abstract Thought for Facing Difficulties and Mental Contrasting for Goal Attainment}

Another topic, which has been raised in the context of rumination by Watkins, is that the specificity of thought can be important in determining whether thinking has beneficial or detrimental consequences. The work by Watkins (e.g., 2008, 2010) has shown that abstract versus more concrete thought can be problematic in maintaining negative affect. Often, sufficiently concrete cognitive processing is necessary to facilitate adaptive thought and behavior (e.g., planning, problem solving). Excessive levels of abstract negative (and probably also positive) spontaneous thinking can undermine concrete steps towards a goal. Similarly, although expectancy of ultimate success is important for well-motivated behavior, fantasizing only about positive outcomes and trouble-free goal-pursuit, rather than thinking about the concrete realities necessary for success, reduces chances of energetic pursuit and of success (Oettingen, 2012). To address these aspects, promising training interventions have been developed to rebalance the proportion and occurrence of abstract versus concrete thought (Watkins et al., 2012) and to tie aspirations to concrete processing of steps necessary to achieve them (Oettingen, 2012), processes that at first almost certainly enlist mental activity beyond that of purely spontaneous thought and the default mode network (Achtziger et al., 2009). Whether the habits of thought developed in these trainings eventually become spontaneous remains to be established.

\section{Conclusions}

Spontaneous thought is a phenomenon that is of long-standing interest to researchers. We have reviewed some of the research showing the clear adaptive as well as maladaptive consequences of this phenomenon. Based on a goal perspective it becomes clear why 
spontaneous thought is so pervasively present in mental life. Moreover, this perspective also casts light on how spontaneous thought can become maladaptive. The progress with regard to methodologies available to study this phenomenon as well as the strong interest in spontaneous thought from philosophical, psychological, and biological traditions renders this field an exciting area for integrated research and theory.

[9114 words of text, including section headings] 


\section{References}

Achtziger, A., Fehr, T., Oettingen, G., Gollwitzer, P. M., \& Rockstroh, B. (2009). Strategies of intention formation are reflected in continuous MEG activity. Social Neuroscience, 4(1), $11-27$.

Andrews-Hanna, J. (2012). The brain's default network and its adaptive role in internal mentation. The Neuroscientist, 18(3), 251-270.

Andrews-Hanna, J., Reidler, J. S., Huang, C., \& Buckner, R. L. (2010). Evidence for the default network’s role in spontaneous cognition. Journal of Neurophysiology, 104, 322-335.

Andrews-Hanna, J. R., Smallwood, J., \& Spreng, R. N. (2014). The default network and selfgenerated thought: component processes, dynamic control, and clinical relevance. Annals of the New York Academy of Sciences, 1316(1), 29-52.

Baars, B. J. (2010). Spontaneous repetitive thoughts can be adaptive: Postscript on “mind wandering.” Psychological Bulletin, 136, 208-210.

Baird, B., Smallwood, J., Mrazek, M. D., Kam, J. W. Y., Franklin, M. S., \& Schooler, J. W. (2012). Inspired by distraction: Mind wandering facilitates creative incubation. Psychological Science, 23, 1117-1122.

Baird, B.. Smallwood, J., \& Schooler, J. W. (2011). Back to the future: Autobiographical planning and the functionality of mind-wandering. Consciousness and Cognition, 20, 1604-1611.

Beck, A. T. (1971/2004). Cognitive Patterns in Dreams and Daydreams. In R. I. Rosner, W. J. Lyddon \& A. Freeman (Eds.), Cognitive Therapy and Dreams (pp. 27-32). New York, 
NY: Springer Publishing Company. (Reprinted from Dream dynamics: Science and psychoanalysis, Vol. 9, pp. 2-9, by J. H. Masserman, Ed., 1971, New York, NY: Grune \& Stratton).

Bennion, K. A., Payne, J. D., \& Kensinger, E. A. (2015). Selective effects of sleep on emotional memory: What mechanisms are responsible? Translational Issues in Psychological Science, 1(1), 79-88.

Bigelsen, J., \& Schupak, C. (2011). Compulsive fantasy: Proposed evidence of an under-reported syndrome through a systematic study of 90 self-identified non-normative fantasizers. Consciousness and Cognition, 20(4), 1634-1648.

Bock, M., \& Klinger, E. (1986). Interaction of emotion and cognition in word recall. Psychological Research, 48, 99-106.

Bos, M. W., Dijksterhuis, A., \& van Baaren, R. B. (2008). On the goal-dependency of unconscious thought. Journal of Experimental Social Psychology, 44(4), 1114-1120.

Buckner, R.L., Andrews-Hanna, J.R., \& Schacter, D.L. (2008). The brain's default network. Annals of the New York Academy of Sciences, 1124 (1), 1-38.

Chatard, A., \& Selimbegović, L. (2011). When self-destructive thoughts flash through the mind: Failure to meet standards affects the accessibility of suicide-related thoughts. Journal of Personality and Social Psychology, 100(4), 587-605.

Christoff, K (2012). Undirected thought: Neural determinants and correlates. Brain Research, 1428, 51-59. 
Christoff, K., Gordon, A. M., Smallwood. J., Smith, R., \& Schooler J. W. (2009). Experience sampling during fMRI reveals default network and executive system contributions to mind wandering. Proceedings of the National Academy of Sciences of the United States, 106, 8719-8724.

Christoff, K., Gordon, A. M., \& Smith, R. (2011). The role of spontaneous thought in human cognition. In Neuroscience of decision making. (pp. 259-284). New York, NY, US: Psychology Press, New York, NY.

Christoff, K., Ream, J. M., \& Gabrieli, J. D. (2004). Neural basis of spontaneous thought processes. Cortex, 40(4), 623-630.

Cox, W. M., Fadardi, J. S., Hosier, S. G., \& Pothos, E. M. (2015). Differential effects and temporal course of attentional and motivational training on excessive drinking. Experimental and Clinical Psychopharmacology, 23(6), 445-454.

Cox, W. M., Heinemann, A. W., Miranti, S. V., Schmidt, M., Klinger, E., \& Blount, J. (2003). Outcomes of Systematic Motivational Counseling for substance use following traumatic brain injury. Journal of Addictive Diseases, 22, 93-110.

Cox, W. M., \& Klinger, E. (2011a). Measuring motivation: The Motivational Structure Questionnaire, Personal Concerns Inventory, and their variants. In W. M. Cox \& E. Klinger (Eds.). Handbook of motivational counseling (2 ${ }^{\text {nd }}$ ed.) (pp. 161-204). Chichester, UK: Wiley.

Cox, W. M., \& Klinger, E. (2011b). Systematic Motivational Counseling: From motivational assessment to motivational change. In W. M. Cox \& E. Klinger (Eds.). Handbook of motivational counseling ( ${ }^{\text {nd }}$ ed.) (pp. 276-302). Chichester, UK: Wiley. 
Cox, W. M., Schippers, G. M., Klinger, E., Skutle, A., Stuchlíková, I., Man, F., King, A. L., \& Inderhaug, R. (2002). Motivational structure and alcohol use of university students with consistency across four nations. Journal of Studies on Alcohol, 63, 280-285.

Dijksterhuis, A., Bos, M. W., Nordgren, L. F., \& Van Baaren, R. B. (2006). On making the right choice: The deliberation-without-attention effect. Science, 311(5763), 1005-1007.

Dijksterhuis, A., \& Meurs, T. (2006). Where creativity resides: The generative power of unconscious thought. Consciousness and Cognition: An International Journal, 15(1), 135-146.

Dijksterhuis, A., \& Nordgren, L. F. (2006). A theory of unconscious thought. Perspectives on Psychological Science, 1(2), 95-109.Epel, E. S., Puternam, E., Lin, J., Blackbunr, E., Lazaro, A., \& Mendes, W. B. (2013). Wandering Minds and Aging Cells. Clinical Psychological Science, 1(1), 75-83.

Domhoff, G. W., \& Fox, K. C. R. (2015). Dreaming and the default network: A review, synthesis, and counterintuitive research proposal. Consciousness and Cognition, 33, $342-353$.

Epel, E. S., Puterman, E., Lin, J., Blackburn, E., Lazaro, A., \& Mendes, W. B. (2013). Wandering minds and aging cells. Clinical Psychological Science, 1(1), 75-83.

Fadardi, J. S., \& Cox, W. M. (2008). Alcohol-attentional bias and motivational structure independently predict alcohol consumption in social drinkers. Drug and Alcohol Dependence, 97, 247-256. 
Fadardi, J. S., \& Cox, W. M. (2009). Reversing the sequence: Reducing alcohol consumption by overcoming alcohol attentional bias. Drug and Alcohol Dependence, 101, 137-145.

Féré, C. S. (1892/1899). The Pathology of Emotions. Transl. R. Park (Watford: University Press).

Fox, K. C., Spreng, R. N., Ellamil, M., Andrews-Hanna, J. R., \& Christoff, K. (2015). The wandering brain: Meta-analysis of functional neuroimaging studies of mind-wandering and related spontaneous thought processes. Neuroimage, 111, 611-621.

Fox, K. C., Thompson, E., Andrews-Hanna, J. R., \& Christoff, K. (2014). Is thinking really aversive? A commentary on Wilson et al.'s “Just think: the challenges of the disengaged mind”. Frontiers in psychology, 5. http://journal.frontiersin.org/article/10.3389/fpsyg.2014.01427/full

Franklin, M. S., Broadway, J. M., Mrazek, M. D., Smallwood, J., \& Schooler, J. W. (2013). Window to the wandering mind: Pupillometry of spontaneous thought while reading. The Quarterly Journal of Experimental Psychology, 66(12), 2289-2294.

Fritzsche, A., Schlier, B., Oettingen, G., \& Lincoln, T. M. (2016). Mental contrasting with implementation intentions increases goal-attainment in individuals with mild to moderate depression. Cognitive Therapy and Research, DOI 10.1007/s10608-015-9749-6.

Fuhrmann, A., Schroer, B. M., \& de Jong-Meyer, R. (2011). Systematic Motivational Counseling in groups: Promoting therapeutic change through client interaction. In W. M. Cox \& E. Klinger (Eds.). Handbook of motivational counseling ( $2^{\text {nd }}$ ed.) (pp. 303-327). Chichester, UK: Wiley. 
Gilboa-Schechtman, E., Revelle, W., \& Gotlib, I. H. (2000). Stroop interference following mood induction: Emotionality, mood congruence and concern relevance. Cognitive Therapy and Research, 24(5), 491-502.

Gollwitzer, P. M. (1990). Action phases and mind-sets. In E. T. Higgins \& R.M. Sorrentino (Eds.), Handbook of motivation and cognition: Foundations of social behavior, Vol. 2 (pp. 53-92). New York: Guilford.

Gollwitzer, P. M., Heckhausen, H., \& Ratajczak, H. (1990). From weighing to willing: Approaching a change decision through pre- or postdecisional mentation. Organizational Behavior and Human Decision Processes, 45(1), 41-65.

Grol, M., Hertel, P. T., Koster, E. H. W., \& De Raedt, R. (2015). The effects of rumination induction on attentional breadth for self-related information. Clinical Psychological Science, 3, 607-618.

Gruberger, M., Ben-Simon, E., Levkovitz, Y., Zangen, A., \& Hendler, T. (2011). Towards a neuroscience of mind-wandering. Frontiers in Human Neuroscience, 5 doi:http://dx.doi.org/10.3389/fnhum.2011.00056.

Handy, T. C., \& Kam, J. W. Y. (2015). Mind wandering and selective attention to the external world. Canadian Journal of Experimental Psychology/Revue Canadienne De Psychologie Expérimentale, 69(2), 183-189.

Hawksley, J., \& Davey, G. C. L. (2010). Mood-as-input and depressive rumination. Behaviour Research and Therapy, 48(2), 134-140. 
Hayes, S. C., Wilson, K. G., Gifford, E. V., Follette, V. M., \& Strosahl, K. (1996). Experiential avoidance and behavioral disorders: A functional dimensional approach to diagnosis and treatment. Journal of Consulting and Clinical Psychology, 64(6), 1152-1168.

Hertel, P. T. (2004). Memory for emotional and non-emotional events in depression: A question of habit. In D. Reisberg \& P. Hertel (Eds.), Memory and emotion (pp. 186 -216). New York, NY: Oxford University Press.

Hoelscher, T. J., Klinger, E., \& Barta, S. G. (1981). Incorporation of concern- and nonconcern-related verbal stimuli into dream content. _Journal of Abnormal Psychology, 49, 88-91.

Hoorelbeke, K., Koster, E. H., Vanderhasselt, M. A., Callewaert, S., \& Demeyer, I. (2015). The influence of cognitive control training on stress reactivity and rumination in response to a lab stressor and naturalistic stress. Behaviour research and therapy, 69, 1-10.

Johannessen, K. B., Oettingen, G., \& Mayer, D. (2012). Mental contrasting of a dieting wish improves self-reported health behaviour. Psychology \& Health, 27, 43-58.

Johnsen, B. H., Laberg, J. C., Cox, W. M., Vaksdal, A., \& Hugdahl, K. (1994). Alcoholic subjects' attentional bias in the processing of alcohol-related words. Psychology of Addictive Behaviors, 8(2), 111-115.

Kam, J. W. Y., Dao, E., Stanciulescu, M., Tildesley, H., \& Handy, T. C. (2013). Mind wandering and the adaptive control of attentional resources. Journal of Cognitive Neuroscience, 25(6), 952-960. 
Kam, J. W. Y., \& Handy, T. C. (2014). Differential recruitment of executive resources during mind wandering. Consciousness and Cognition, 26, 51-63.

Kam, J. W. Y., Nagamatsu, L. S., \& Handy, T. C. (2014). Visual asymmetry revisited: Mind wandering preferentially disrupts processing in the left visual field. Brain and Cognition, 92, 32-38.

Kam, J. W. Y., Xu, J., \& Handy, T. C. (2014). I don’t feel your pain (as much): The desensitizing effect of mind wandering on the perception of others' discomfort. Cognitive, Affective \& Behavioral Neuroscience, 14(1), 286-296.

Killingsworth, M. A., \& Gilbert, D. T. (2010). A wandering mind is an unhappy mind. Science, 330, 932.

Klinger, E. (1971). Structure and functions of fantasy. N.Y.: Wiley.

Klinger, E. (1975). Consequences of commitment to and disengagement from incentives. Psychological Review, 82, 1-25.

Klinger, E. (1977). Meaning and void: Inner experience and the incentives in people's lives. Minneapolis: University of Minnesota Press.

Klinger, E. (1978). Modes of normal conscious flow. In K. S. Pope \& J. L. Singer Eds.), The stream of consciousness: Scientific investigations into the flow of human experience (pp. 225-258). New York: Plenum, 1978.

Klinger, E. (1987). The Interview Questionnaire technique: Reliability and validity of a mixed idiographic-nomothetic measure of motivation. In J. N. Butcher \& C. D. Spielberger 
(Eds.), Advances in personality assessment (Vol. 6; pp. 31-48). Hillsdale, New Jersey: Erlbaum.

Klinger, E. (1990). Daydreaming. Los Angeles, CA: Tarcher (Putnam).

Klinger, E. (1996). Emotional influences on cognitive processing, with implications for theories of both. In P. Gollwitzer \& J. A. Bargh (Eds.), The psychology of action: Linking cognition and motivation to behavior (pp. 168-189). New York: Guilford.

Klinger, E. (2009). Daydreaming and fantasizing: Thought flow and motivation. In K. D. Markman, W. M. P. Klein, and J. A. Suhr (Eds), Handbook of imagination and mental simulation (pp. 225-239). New York: Psychology Press.

Klinger, E. (2013). Goal commitments and the content of thoughts and dreams: Basic principles. Frontiers in Psychology, 4, doi: 10.3389/fpsyg.2013.00415.

Klinger, E., Barta, S.G., \& Maxeiner, M.E. (1980). Motivational correlates of thought content frequency and commitment. Journal of Personality and Social Psychology, 39, 1222-1237.

Klinger, E., \& Cox, W. M. (1987-1988). Dimensions of thought flow in everyday life. Imagination, Cognition and Personality, 7, 105- 128.

Klinger, E., \& Cox, W. M. (2011a). Motivation and the goal theory of current concerns. In W. M. Cox \& E. Klinger (Eds.), Handbook of motivational counseling (2 ${ }^{\text {nd }}$ ed.) (pp. 3-47). Chichester, UK: Wiley.

Klinger, E., \& Cox, W. M. (2011b). The Motivational Structure Questionnaire, Personal Concerns Inventory, and their variants: Psychometric properties. In W. M. Cox \& E. 
Klinger (Eds.). Handbook of motivational counseling (2nd ed.) (pp. 205-232).

Chichester, UK: Wiley.

Klug, H. J. P., \& Maier, G. (2015). Linking goal progress and subjective well-being: A metaanalysis. Journal of Happiness Studies, 16(1), 37-65.

Kopp, K., D’Mello,S., \& Mills, C. (2015). Influencing the occurrence of mind wandering while reading. Consciousness and Cognition, 34, 52-62.

Kosslyn, S. M., Thompson, W. L., \& Alpert, N. M. (1997). Neural systems shared by visual imagery and visual perception: A positron emission tomography study. NeuroImage, 6, 320-334.

Koster, E. H. W., \& Bernstein, A. (2015). Introduction to the special issue on cognitive bias modification: Taking a step back to move forward? Journal of Behavior Therapy and Experimental Psychiatry, 49, 1-4.

Koster, E. H. W., De Lissnyder, E., Derakshan, N., \& De Raedt, R. (2011). Understanding depressive rumination from a cognitive science perspective: The impaired disengagement hypothesis. Clinical Psychology Review, 31(1), 138-145.

Larsen, R., \& Diener, E. ( 1987). Affect intensity as an individual difference characteristic. Journal of Research in Personality, 21, 1-39.

Lyubomirsky, S., \& Nolen-Hoeksema, S. (1995). Effects of self-focused rumination on negative thinking and interpersonal problem solving. Journal of Personality and Social Psychology, 69(1), 176-190. 
Marchetti, I., Koster, E. H. W., \& De Raedt, R. (2013). Rest-Related Dynamics of Risk and Protective Factors for Depression: A Behavioral Study Clinical Psychological Science, 1(4), 443-451.

Marchetti, I., Koster, E.H.W., Klinger, E., \& Alloy, L.B. (2016). Spontaneous Thought and Vulnerability to Mood Disorders: The Dark Side of the Wandering Mind. Clinical Psychological Science. doi: 10.1177/2167702615622383

Marchetti, I. Van de Putte, E., \& Koster, E.H.W. (2014). Self-generated thoughts and depression: From daydreaming to depressive symptoms. Frontiers in Human Neuroscience, 8, 13.

Martin, L. L., \& Tesser, A. (1989). Toward a motivational and structural theory of ruminative thought. In J. S. Uleman \& J. A. Bargh (Eds.), Unintended thought (pp. 306 -326). New York, NY: Guilford Press.

Martin, L. L., \& Tesser, A. (1996). Some ruminative thoughts. In R. S. Wyer (Ed.), Ruminative thoughts. Advances in social cognition (Vol. 9, pp. 1-47). Hillsdale, NJ: Erlbaum.

Mason, M. F., Norton, M. I., Van Horn, J. D., Wegner, D. M.,Grafton, S. T., \& Macrae, C. N. (2007). Wandering minds: The default network and stimulus-independent thought. Science, 315, 393-395.

Mooneyham, B.W., \& Schooler, J.W. (2013). The costs and benefits of mindwandering: A review. Canadian Journal of Experimental Psychology, 67, 11-18.

McDevitt, E. A., Duggan, K. A., \& Mednick, S. C. (2014). Rem sleep rescues learning from interference. Neurobiology of Learning and Memory, doi:http://dx.doi.org/10.1016/j.nlm.2014.11.015. 
McVay, J. C., \& Kane, M. J. (2013). Dispatching the wandering mind? toward a laboratory method for cuing "spontaneous" off-task thought. Frontiers in Psychology, 4 doi:http://dx.doi.org/10.3389/fpsyg.2013.00570.

Mrazek, M. D., Phillips, D. T., Franklin, M. S., Broadway, J. M., \& Schooler, J. W. (2013). Young and restless: Validation of the mind-wandering questionnaire (MWQ) reveals disruptive impact of mind-wandering for youth. Frontiers in Psychology, 4.

Mooneyham, B.W., \& Schooler, J.W. (2013). The costs and benefits of mindwandering: A review. Canadian Journal of Experimental Psychology, 67, 11-18.

Nagamatsu, L. S., Kam, J. W. Y., Liu-Ambrose, T., Chan, A., \& Handy, T. C. (2013). Mindwandering and falls risk in older adults. Psychology and Aging, 28(3), 685-691.

Nenkov, G. Y., \& Gollwitzer, P. M. (2012). Pre- versus postdecisional deliberation and goal commitment: The positive effects of defensiveness. Journal of Experimental Social Psychology, 48(1), 106-121.

Nieuwenstein, M. R., Wierenga, T., Morey, R. D., Wicherts, J. M., Blom, T. N., Wagenmakers, E. J., \& van Rijn, H. (2015). On making the right choice: a meta-analysis and large-scale replication attempt of the unconscious thought advantage. Judgment and Decision Making, 10, 1-17. 
Nikles, C. D. II, Brecht, D. L., Klinger, E., \& Bursell, A. L. (1998). The Effects of currentconcern- and nonconcern-related waking suggestions on nocturnal dream content. Journal of Personality and Social Psychology, 75, 242-255.

Nikula, R., Klinger, E., \& Larson-Gutman, M. K. (1993). Current concerns and electrodermal reactivity: Responses to words and thoughts. Journal of Personality, 61, 63-84.

Nolen-Hoeksema, S. (1991). Responses to Depression and Their Effects on the Duration of Depressive Episodes. Journal of Abnormal Psychology, 100(4), 569-582.

Nolen-Hoeksema, S., Wisco, B. E., \& Lyubomirsky, S. (2008). Rethinking Rumination. Perspectives on Psychological Science, 3(5), 400-424.

Oettingen, G. (1996). Positive fantasy and motivation. In P. Gollwitzer \& J. A. Bargh (Eds.), The psychology of action: Linking cognition and motivation to behavior (pp. 236-259). New York, NY: Guilford Press.

Oettingen, G. (2012). Future thought and behaviour change. European Review of Social Psychology, 23, 1-63.

Oettingen, G., Pak, H., \& Schnetter, K. (2001). Self-regulation of goal-setting: Turning free fantasies about the future into binding goals. Journal of Personality and Social Psychology, 80(5), 736-753.

Ottaviani, C., \& Couyoumdjian, A. (2013). Pros and cons of a wandering mind: A prospective study. Frontiers in Psychology, 4 (August 14, 2013).

Ottaviani, C., Shapiro, D., \& Couyoumdjian, A. (2013). Flexibility as the key for somatic health: From mind wandering to perseverative cognition. Biological Psychology, 94(1), 38-43. 
Pace-Schott, E., Germain, A., \& Milad, M. R. (2015). Effects of sleep on memory for conditioned fear and fear extinction. Psychological Bulletin, doi:http://dx.doi.org/10.1037/bul0000014.

Poerio, G. L., Totterdell, P., \& Miles, E. (2013). Mind-wandering and negative mood: Does one thing really lead to another? Consciousness and Cognition: An International Journal, 22(4), 1412-1421.

Pope, K. S. (1977). The flow of consciousness. Unpublished Ph. D. dissertation, Yale University.

Raichle, M. E. (2009). A paradigm shift in functional brain imaging. The Journal of Neuroscience, 29(41), 12729-12734.

Raichle, M. E., MacLeod, A. M., Snyder, A. Z., Powers, W. J., Gusnard, D. A., \& Shulman, G. L. (2001) A default mode of brain function. Proceedings of the National Academy of Sciences, U. S. A., 98, 676-682.

Riemann, B. C. \& McNally, R. J. (1995). Cognitive processing of personally-relevant information. Cognition and Emotion, 9, 325-340.

Roberts, H., Watkins, E. R., \& Wills, A. J. (2013). Cueing an unresolved personal goal causes persistent ruminative self-focus: An experimental evaluation of control theories of rumination. Journal of Behavior Therapy and Experimental Psychiatry, 44(4), 449-455.

Rummel, J., \& Boywitt, C. D. (2014). Controlling the stream of thought: Working memory capacity predicts adjustment of mind-wandering to situational demands. Psychonomic Bulletin \& Review, 21(5), 1309-1315. 
Schacter, D. L. (2012). Adaptive constructive processes and the future of memory. American Psychologist, 67, 603-613.

Schneider, W. (1987). Ablenkung und Handlungskontrolle: Eine kognitiv-motivationale Perspektive. Unpublished Diploma thesis, University of Bielefeld.

Schupak, C., \& Rosenthal, J. (2009). Excessive daydreaming: A case history and discussion of mind wandering and high fantasy proneness. Consciousness and Cognition, 18, 290-292.

Sheeran, P., Harris, P., Vaughan, J., Oettingen, G., \& Gollwitzer, P. M. (2013). Gone exercising: Mental contrasting promotes physical activity among overweight, middle-aged, low-SES fishermen. Health Psychology, 32(7), 802-809.

Singer, J. L. (1966). Daydreaming: An introduction to the experimental study of inner experience. New York: Random House.

Singer, J. L. (2009). Researching imaginative play and adult consciousness: Implications for daily and literary creativity. Psychology of Aesthetics, Creativity, and the Arts 3, 190199.

Smallwood, J., \& Andrews-Hanna, J. (2013). Not all minds that wander are lost: The importance of a balanced perspective on the mind-wandering state. Frontiers in Psychology, 4 (Aug 16, 2013).

Smallwood, J., Nind, L., \& O’Connor, R. C. (2009). When is your head at? An exploration of the factors associated with the temporal focus of the wandering mind. Consciousness and Cognition: An International Journal, 18(1), 118-125.

Smallwood, J., \& O'Connor, R. C. (2011). Imprisoned by the past: Unhappy moods lead to a retrospective bias to mind wandering. Cognition and Emotion, 25, 1481-1490. 
Smallwood, J., Ruby, F. J. M., \& Singer, T. (2013). Letting go of the present: Mind-wandering is associated with reduced delay discounting. Consciousness and Cognition, 22, 1-7.

Smallwood, J., Schooler, J. W., Turk, D. J., Cunningham, S. J., Burns, P., \& Macrae, C. N. (2011). Self-reflection and the temporal focus of the wandering mind. Consciousness and Cognition, 20 (4), 1120-1126.

Smallwood, J., Tipper, C., Brown, K., Baird, B., Engen, H., Michaels, J. R., Schooler, J. W. (2013). Escaping the here and now: Evidence for a role of the default mode network in perceptually decoupled thought. NeuroImage, 69, 120-125.

Smith, J. M., \& Alloy, L. B. (2009). A roadmap to rumination: A review of the definition, assessment, and conceptualization of this multifaceted construct. Clinical Psychology Review, 29(2), 116-128.

Spasojevic, J., \& Alloy, L. B. (2001). Rumination as a Common Mechanism Relating Depressive Risk Factors to Depression. Emotion, 1(1), 25-37.

Spreng, R. N., Mar, R. A., \& Kim, A. S. N. (2009). The common neural basis of autobiographical memory, prospection, navigation, theory of mind, and the default mode: A quantitative meta-analysis. Journal of Cognitive Neuroscience, 21(3), 489-510.

Spreng, R. N., Stevens, W. D., Chamberlain, J. P., Gilmore, A. W., \& Schacter, D. L. (2010). Default network activity, coupled with the frontoparietal control network, supports goaldirected cognition. NeuroImage, 53, 303-317.

Stawarczyk, D., Majerus, S., \& D'Argembeau, A. (2013). Concern-induced negative affect is associated with the occurrence and content of mind-wandering. Consciousness and Cognition, 22(2), 442-448. 
Stawarczyk, D., Majerus, S., Van der Linden, M., \& D’Argembeau, A. (2012). Using the daydreaming frequency scale to investigate the relationships between mind-wandering, psychological well-being, and present-moment awareness. Frontiers in Psychology, 3; doi:http://dx.doi.org/10.3389/fpsyg.2012.00363.

Stawarczyk, D., Majerus, S., Maj, M., Van der Linden, M., \& D'Argembeau, A. (2011a). Mindwandering: Phenomenology and function as assessed with a novel experience sampling method. Acta Psychologica, 136, 370-381.

Stawarczyk, D., Majerus, S., Maquet, P., \& D'Argembeau, A. (2011b). neural correlates of ongoing conscious experience: Both task-unrelatedness and stimulus-independence are related to default network activity. PLoS One, 6 (2), e16997.

Tellegen, A., Lykken, D. T., Bouchard, T. J., Wilcox, K. J., Segal, N. L., \& Rich, S. (1988). Personality similarity in twins reared apart and together. Journal of Personality and Social Psychology, 54(6), 1031-1039.

Thomson, D. R., Ralph, B. C. W., Besner, D., \& Smilek, D. (2015). The more your mind wanders, the smaller your attentional blink: An individual differences study. The Quarterly Journal of Experimental Psychology, 68(1), 181-191.

Treynor, W., Gonzalez, R., \& Nolen-Hoeksema, S. (2003). Rumination reconsidered: A psychometric analysis. Cognitive Therapy and Research, 27(3), 247-259.

Unsworth, N., \& McMillan, B. D. (2014). Fluctuations in pre-trial attentional state and their influence on goal neglect. Consciousness and Cognition: An International Journal, 26, 90-96. 
Vogt, J., Lozo, L., Koster, E.H.W., \& De Houwer, J. (2011). On the role of goal relevance in emotional attention: Disgust evokes early attention to cleanliness. Cognition \& Emotion, 25, 466-477.

Watkins, E. R. (2008). Constructive and unconstructive repetitive thought. Psychological Bulletin, 134(2), 163-206.

Watkins, E. R. (2010). Level of construal, mind wandering, and repetitive thought: Reply to McVay and Kane (2010). Psychological Bulletin, 136(2), 198-201.

Watkins, E., Grafton, B., Weinstein, S. M., \& MacLeod, C. (2015). For ruminators, the emotional future is bound to the emotional past: heightened ruminative disposition is characterized by increased emotional extrapolation. Clinical Psychological Science, 3, 648-658.

Watkins, E.R., \& Nolen-Hoeksema, S. (2014). A habit-goal framework of depressive rumination. Journal of Abnormal Psychology, 123, 24-34.

Watkins, E. R., Taylor, R. S., Byng, R., Baeyens, C., Read, R., Pearson, K., et al. (2012). Guided self-help concreteness training as an intervention for major depression in primary care: a Phase II randomized controlled trial. Psychological Medicine, 42(7), 1359-1371.

Whitmer, A. J., \& Gotlib, I. H. (2013). An attentional scope model of rumination. Psychological Bulletin, 139(5), 1036-1061. 